\title{
The Shackleton incident could profit international law
}

THE incident at sea last week, in which the British research ship Shackleton had to make rapidly for port in the Falkland Islands after a warning shot had been fired across its bows by the Argentine destroyer Almirante Storni, must not be seen simply as an isolated event connected with a territorial dispute and a trigger-happy captain. In recent years the freedom of marine scientists to do pretty well what they wanted even within sight of foreign territory has been rapidly eroded, and there is no sign that when the Law of the Sea conferences have run their course life will be much easier for those who need to come fairly close to foreign coastlines. The point which should be abundantly clear is that Argentina is prepared (not for the first time) to take strong action against infringements of what she regards as her own economic zone by research vessels. She, along with many other countries, has sought to have the power to regulate scientific research within that zone.

The research conducted from Shackleton used conventional geophysical techniques: magnetometry, gravimetry and refraction and reflection seismology. Most of it was being carried out in deep water in the Scotia Sea, and the programme, under the supervision of Birmingham University, has been running for many years. The purpose of the work is to attempt to put the unique area area off South America into a plate tectonic context.

Those countries, Britain included, which have attempted

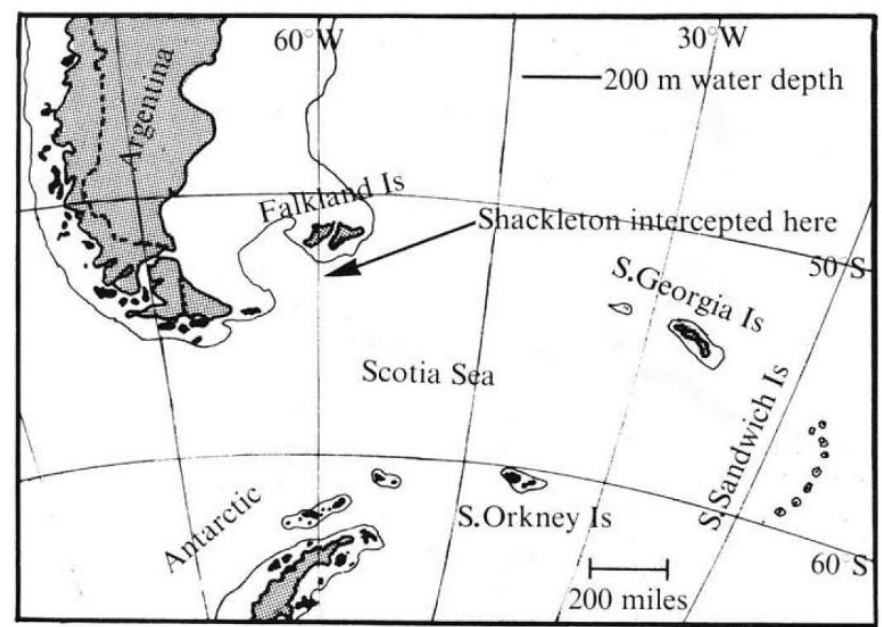

to produce guidelines for international discussion on what is pure and what is applied research would almost certainly rate Shackleton's operations as 'pure'. But it is not as simple as that. Theories of the regional evolution of the Earth's crust have a lot in them for the economic geologist and thus for the prospecting industry; a clear picture of past geological history will not point a finger at exactly where hydrocarbons will be found, but it will provide some helpful signposts. Reasonably, scientists may protest that their work is the pursuit of knowledge for its own sake, that it is not supported by commercial interests, and that their results will be available internationally. But equally reasonably, countries with inadequately developed technology and expertise to capitalise on this information may feel themselves consistently outmanoeuvred when it comes to negotiating exploration rights. Their only defence then may be to demand some sort of technical assistance in exchange for access.

In a month's time the Law of the Sea Conference will resume in New York, and among other things will attempt to come to terms with a 'single negotiating text' including draft articles on marine scientific research. It is likely that the coastal state in whose economic zone another nation wishes to perform research will be called upon to decide whether the research is 'pure' or 'applied' and, in the former case, presumably to grant permission without too many strings attached. An appeal procedure to international experts is proposed if agreement cannot be reached. This seems a much better approach than any attempt by the United Nations to produce a universally acceptable list of topics to be regarded as pure.

It will be a pity if the Shackleton affair cannot be viewed at the conference as more than a territorial dispute. For, squabbles apart, it provides a rather good concrete example of the sort of research operation that is going to give rise to international disagreement; yet there is no reason why intelligent give and take on technology transfer and technical advice should not resolve such disputes. If this incident could be freed from its accretions of diplomatic conflict and considered simply as an ideal case for the Law of the Sea Conference to consider when legislating, some good could come of it. But it will need a certain detachment from the British delegation. $\square$ 